NBER WORKING PAPER SERIES

\title{
STRENGTHENING NATIONAL DATA TO BETTER MEASURE WHAT WE ARE BUYING IN HEALTH CARE: RECONCILING NATIONAL HEALTH EXPENDITURES WITH DETAILED SURVEY DATA
}

\author{
Allison B. Rosen \\ Kaushik Ghosh \\ Emily S. Pape \\ Marcelo Coca Perraillon \\ Irina Bondarenko \\ Kassandra L. Messer \\ Trivellore Raghunathan \\ Susan T. Stewart \\ David M. Cutler \\ Working Paper 23290 \\ http://www.nber.org/papers/w23290 \\ NATIONAL BUREAU OF ECONOMIC RESEARCH \\ 1050 Massachusetts Avenue \\ Cambridge, MA 02138 \\ March 2017
}

This research was supported by P01AG031098 \& R37AG047312 from the National Institute of Aging and UL1TR000161 from the National Center for Research Resources. The views expressed herein are those of the authors and do not necessarily reflect the views of the National Bureau of Economic Research.

At least one co-author has disclosed a financial relationship of potential relevance for this research. Further information is available online at http://www.nber.org/papers/w23290.ack

NBER working papers are circulated for discussion and comment purposes. They have not been peer-reviewed or been subject to the review by the NBER Board of Directors that accompanies official NBER publications.

(C) 2017 by Allison B. Rosen, Kaushik Ghosh, Emily S. Pape, Marcelo Coca Perraillon, Irina Bondarenko, Kassandra L. Messer, Trivellore Raghunathan, Susan T. Stewart, and David M. Cutler. All rights reserved. Short sections of text, not to exceed two paragraphs, may be quoted without explicit permission provided that full credit, including () notice, is given to the source. 
Strengthening National Data to Better Measure What We Are Buying in Health Care: Reconciling National Health Expenditures with Detailed Survey Data

Allison B. Rosen, Kaushik Ghosh, Emily S. Pape, Marcelo Coca Perraillon, Irina Bondarenko, Kassandra L. Messer, Trivellore Raghunathan, Susan T. Stewart, and David M. Cutler NBER Working Paper No. 23290

March 2017

JEL No. I1

\begin{abstract}
$\underline{\text { ABSTRACT }}$
As health care financing, organization, and delivery innovations proliferate, the need for comprehensive, detailed data on medical spending has never been more apparent. This study builds on previous work to provide a more comprehensive accounting of medical spending at the individual level than has been done in the past. We account for spending by the entire population: the civilian, non-institutionalized population that is the subject of past studies, as well as high medical spenders, the institutionalized, the incarcerated, and active-duty military personnel. We use within-imputation and other adjustments to build a micro dataset and reconcile survey data based on our estimate of medical spending to the National Health Expenditure Accounts (NHEA). The micro dataset we build can be used for more detailed policy evaluations that more closely reflect true national personal health expenditure at the individual level.
\end{abstract}

Allison B. Rosen

Department of Quantitative Health Sciences

University of Massachusetts Medical School

368 Plantation Street, AS9-1083

Worcester, MA 01605

and NBER

Allison.Rosen@umassmed.edu

Kaushik Ghosh

NBER

1050 Massachusetts Ave.

Cambridge, MA 02138

ghoshk@nber.org

Emily S. Pape

Care Compass Network

emilyspape@gmail.com

Marcelo Coca Perraillon

University of Colorado, Denver

13001 E. 17th Place

B119 Bldg. 500, Rm E3312

Aurora, CO 80045

marcelo.perraillon@ucdenver.edu
Kassandra L. Messer

University of Michigan

kasey@umich.edu

Trivellore Raghunathan

University of Michigan

teraghu@umich.edu

Susan T. Stewart

NBER

1050 Massachusetts Ave

Cambridge, MA 02138

sstewart@nber.org

David M. Cutler

Department of Economics

Harvard University

1875 Cambridge Street

Cambridge, MA 02138

and NBER

dcutler@harvard.edu

Irina Bondarenko

University of Michigan

ibond@med.umich.edu 


\section{Introduction}

Accurately and comprehensively tracking health care spending by Americans is a central focus of U.S. government agencies, economists and health service researchers (Rosen and Cutler, 2007, 2009; Aizcorbe et al., 2008). The National Health Expenditure Accounts (NHEA) maintained by the Centers for Medicare and Medicaid Services (CMS) track spending on direct medical care and other health-related activities (public health, research, etc.) for the entire U.S. population (NHEA, CMS, 1960-2014). However, the NHEA do not provide a sample of individuals with their associated spending. For this reason they cannot be used to study trends in the concentration of spending by certain populations or for certain types of services beyond broadly aggregated categories.

For these more disaggregated types of analyses, researchers generally depend on person or household level surveys of medical utilization and expenditure. These surveys, including the Medical Expenditure Panel Survey (MEPS) and Medicare Current Beneficiary Survey (MCBS), offer detailed claims and/or self-reported information for each medical service used by survey respondents. While offering greater detail, micro surveys are generally limited in scope in terms of their study populations and health services. For example, the MEPS excludes individuals residing in nursing homes and other facilities, as well as active duty military personnel. Further, the MEPS is known to underestimate total spending, especially by high-spenders, because of its reliance on self-report of expenditures (Zuvekas et al. 2009). The MCBS is only for the Medicare population, omitting a huge portion of total medical dollars. Nevertheless, each of these surveys is useful for cost-effectiveness analyses, and other policy related studies of medical expenditure requiring individual-level data. 
In this paper, we present a methodology for adjusting micro surveys to match national medical spending. Our final product is an individual-level data set of medical spending matching national total spending that allows for analysis of subpopulations and trends and that is not limited in its covered population.

We are not the first to attempt such reconciliation. Past research by Arnett et al. (1990), Fisher (1980), Waldo et al. (1989), Meara et al. (2004), Selden et al. (2001), Sing et al. (2006), and Bernard et al. (2012), has also proceeded along these lines. A number of other studies have used these results in further analyses (Ormond et al., 2011; Finkelstein et al., 2009; Roehrig et al., 2009). However, these studies have been limited to the non-institutionalized civilian population; effectively, this excludes roughly 32 percent of personal health care (PHC) spending in the NHEA (Sing et al., 2006; Rosen and Cutler, 2009). Our analysis expands upon this earlier work by CMS and AHRQ to include the entire U.S. population, thus allowing for a much richer analysis of medical spending. We also pay particular attention to spending of high cost individuals.

We focus on medical spending in 2002 in order to directly compare our findings with a reconciliation of the 2002 MEPS and NHEA (Sing et al., 2006). Although a more recent reconciliation exists for 2007 (Bernard et al., 2012), our work also includes additional sources of information about non-covered populations.

We align the NHEA spending and survey-reported spending in terms of covered services (e.g., hospital care, prescription drugs, etc.) and covered populations (e.g., Medicare beneficiaries, active duty military, etc.). We exclude only the spending from the PHC-portion of the NHEA that we would not expect (or desire) to be captured by the micro surveys (e.g., hospital non-patient revenue such as from gift shops or parking, spending by non-US residents, 
etc.). To account for missing populations, we use imputation methods to reflect the size and demographic profile of the out-of-scope groups. After aligning populations and covered services, we reconcile the enhanced survey-reported spending with the adjusted NHEA by making a final adjustment to survey-reported spending. The resulting data matches NHEA totals and accounts for a comprehensive swath of the US population.

The rest of the paper is as follows. Section I discusses the data on medical spending. Sections II and III describe the reconciliation methods in detail. Section IV presents our results and offers the main conclusions.

\section{Data}

Data on aggregate national health expenditures are provided in the National Health Expenditure Accounts (NHEAs) produced annually by the Centers for Medicare and Medicaid Services (CMS). Within the broad category of health spending, we focus on personal health care because it captures spending for therapeutic goods and services also measured by the national micro surveys. Personal health care excludes other health-related endeavors, such as research, construction, public health activities, and the administrative costs of insurance programs. In 2002, personal health care represented about 84 percent of total national health expenditures.

Spending for personal health care can be divided by source of funds and category of service. Categories of service include hospital care, professional services (physicians, clinics, and dentists), nursing homes, home health agencies, and medical products (prescription drugs, durable equipment, and non-durable products).

We use two major surveys to capture individual level healthcare spending. The first one is the Medical Expenditure Panel Survey (MEPS), which covers the civilian non-institutionalized 
population. The second is the 2002 Medicare Current Beneficiary Survey (MCBS), sponsored by CMS and covering Medicare beneficiaries including those in institutions. But, there are several population groups not covered by either of these surveys. The MEPS does not sample residents of health care institutions (nursing facilities, homes for the cognitively impaired, etc.), and neither MEPS nor MCBS include active duty military personnel, incarcerated individuals, institutionalized non-Medicare population.

We account for these populations using several other data sets. To account for the institutionalized non-Medicare population, we use the 2004 National Nursing Home Survey (NNHS). The NNHS is a nationally representative sample of nursing homes, their services, staff, and current residents. The survey collects information on residents' demographic characteristics, health status, sources of payment, use of medications, and services received. Information on people in jails and prisons is obtained from the 2004 Survey of Inmates in State and Federal Correctional Facilities (SISFCF) and 2002 tables published by the Bureau of Justice Statistics (BJS). Information on US deployed active duty military personnel is obtained from the Office of Army Demographics (2003) and Department of Defense (2002). Next, we describe each of the data sources in detail.

\section{National Health Expenditure Accounts}

The National Health Expenditure Accounts are produced annually by the Office of the Actuary at CMS. The NHEA report total spending and its division by source of payment and category of service. This information is summarized in a series of 'sources and uses' of funds tables, published annually and available via download from the CMS website beginning with data from 1960. We use the 2010 edition of the 2002 NHEA. 
The NHEA are developed from a variety of sources. They are based on aggregate provider based revenue data sources, such as the US Census Bureau (the Economic Census and the Service Annual Survey), the American Hospital Association, IMS Health and other government administrative data. They are believed to be an accurate representation of total spending, and represent a major contribution to our understanding of medical expenditures in the U.S. The NHEA offer a comprehensive picture of spending flows over time within the health care system, identifying both the source and the destination of health expenditure. A typical NHEA table for 2002 is shown in Table 1, which reports national health expenditures by source of funds and type of expenditure. Of the estimated $\$ 1,636$ billion in expenditures in 2002, health consumption expenditures are $\$ 1,534$ billion and investment (research and equipment) is $\$ 102$ billion. In this study, we focus only on the Personal Health Care Expenditures (PHC, $\$ 1,372$ billion). This includes therapeutic goods and services rendered to a person to treat or prevent a particular medical condition. Table 1 reports detailed PHC expenditures. PHC service categories include hospital care ( $\$ 486$ billion), physicians ( $\$ 341$ billion), dental services ( $\$ 74$ billion), other professional services ( $\$ 44$ billion), other health, residential and personal care expenditures ( $\$ 78$ billion), home health agencies ( $\$ 37$ billion), nursing homes ( $\$ 94$ billion), prescription drugs ( $\$ 158$ billion), durable medical equipment ( $\$ 27$ billion) and other non-durable medical products (\$33 billion).

\section{Medical Expenditure Panel Survey (MEPS)}

The Medical Expenditure Panel Survey (MEPS was designed to provide detailed information about the nation's changing health care system. Administered by the Agency for Healthcare Research and Quality (AHRQ, the MEPS collects information from several sources 
on the types of health services used by respondents, the cost of these services, and how the services were paid for (Cohen et al. 1996, 1997, 2009). The MEPS sample consists of households that responded to the prior year's National Health Interview Survey (NHIS) and is designed to represent the civilian non-institutionalized U.S. population. The basic unit of analysis is the person, and data are collected for each family member in the household who is eligible for the survey.

The MEPS Household Component (HC) consists of an overlapping panel design in which respondents are interviewed, using a computer-assisted personal interview (CAPI) system, five times over thirty months to collect utilization and expenditure data for a minimum of two consecutive calendar years. A new panel has been introduced each year since the MEPS began in 1996. Expenditure data in the MEPS are primarily self-reported. However, the Medical Provider Component, which surveys medical providers and pharmacies identified by MEPS-HC respondents, serves as an imputation source to reduce the level of bias in survey estimates of medical expenditures due to item non-response and household data of questionable quality. Its purpose is to supplement household reported data and it is not intended to be an independent sample of providers for estimation purposes. The purpose of the multi-source data collection is to build an accurate accounting of health care utilization and expenditure (rather than charges) for the covered population. In addition, detailed information on respondents' insurance coverage, employment, health status and physical functioning, access to care, and demographic and socioeconomic characteristics is available for the study of different population groups.

While the MEPS does well in capturing spending on its covered populations, it excludes certain policy relevant groups. As a survey of the civilian non-institutionalized population, the MEPS does not include residents of health care institutions (nursing facilities, homes for the 
cognitively impaired, etc.), active duty military personnel, incarcerated individuals, citizens living abroad, or non-citizens in the United States. Trends in the concentration of medical spending for certain uses or populations cannot be fully understood using the MEPS alone. Residents of long-term care institutions are arguably the most important group among those excluded, having disproportionately high medical spending. If an individual transitions from the community to a nursing home during a survey wave, none of their medical spending (within or outside of the institution) for the duration of their time in the institution is recorded in MEPS.

To make the MEPS comparable to the NHEA, Sing et al. (2006) made two major exclusions to the NHEA: $\$ 146$ billion for long term care facility expenditures and $\$ 52$ billion for acute care expenditures of institutionalized. Out of a total exclusion of $\$ 377$ billion in Sing et al. (2006), about $\$ 198$ billion (52 percent) is for long term and acute care. Other omitted groups in MEPS include the prison and jail population (Sabol, 2007), those on active military duty, Americans living overseas (estimated at roughly 4 million in 2000 (American Citizens Abroad (ACA), 2008)), and high-spenders (Zuvekas et al., 2009).

\section{Medicare Current Beneficiary Survey (MCBS)}

The Medicare Current Beneficiary Survey (MCBS), sponsored by the Centers for Medicare \& Medicaid Services (CMS), is a nationally representative survey of aged, disabled, and institutionalized Medicare beneficiaries. It over-samples the very old (aged 85 or older) and disabled Medicare beneficiaries (Adler, 1994; CMS, 2008b). The survey uses a rotating panel design whereby panelists are followed over a span of four years, and undergo three interviews each year. Because it is a person-based survey, the MCBS follows people regardless of whether they live in a household or a long-term care facility, or switch between the two during the course 
of the survey period. The MCBS has been administered continuously since 1991 (the baseline interviews). It collects information on the health status, health care utilization, expenditures (both Medicare and non-Medicare payments), health insurance coverage, and socioeconomic and demographic characteristics of the entire spectrum of Medicare beneficiaries (both elderly and disabled).

The central purpose of the MCBS is to collect utilization and source of payment information for all services used by Medicare beneficiaries, including those not covered by Medicare (Adler, 1994). MCBS spending data are believed to be reasonably accurate, as selfreported utilization and expenditure information undergo extensive validation using Medicare claims data. Further, the MCBS's method of tracking respondents in the community and institutions makes it an invaluable source of information on the spending of this under-studied population. MCBS data demonstrate just how critically important expenditure data are for the institutionalized population.

\section{The National Nursing Home Survey (NNHS)}

The National Nursing Home Survey (NNHS) is a set of national sample surveys of nursing homes, their residents, and their staff. Although each of these surveys emphasized different topics, they all provided some common basic information about nursing homes, their residents, and their staff. All nursing homes included in this survey had at least three beds and were either certified (by Medicare or Medicaid) or had a state license to operate as a nursing home. Data on the facilities were collected through face-to-face interviews with the administrators and staff and included bed size, ownership, and staffing. Data obtained on residents included demographic characteristics, functional and health status, diagnoses, services 
received, and sources of payment. Information was collected for up to twelve current residents in each facility.

\section{Medical spending adjustments}

The first step in this reconciliation study is to align the micro surveys of medical spending to the NHEA. Selden et al. (2001) and Sing et al. (2006) attempted these reconciliations between NHEA and MEPS for 1996 and 2002, respectively. In their work, MEPS-reported expenditures were reconciled with the comparable components of NHEA expenditures, omitting those in institutions and their spending. In this study, we make two basic types of adjustments. First, we remove expenditures from the NHEA for goods and services which are out of scope of micro surveys (MEPS, MCBS). Second, we redefine some categories of medical service in the NHEA, MEPS and MCBS (shifting expenditures as appropriate) to create consistent categories between these three sources. These alignments are similar to previous reconciliations between the MEPS and the NHEA.

\section{Exclusions from NHEA}

We focus on the Personal Health Care (PHC) portion of the NHEA which, in 2002, totaled $\$ 1.34$ trillion. We exclude expenditures not directly related to patient care from the PHC (Table 1); such as net cost to health insurance $(\$ 88,927)$, government administrative expenses (\$21,624 million) and public health activities (\$51,870 million), spending on research $(\$ 32,016$ million) and structures and equipment (\$70,028 million), which are not covered in the MEPSMCBS. Beyond these non-PHC adjustments, there are five personal health care spending items 
that need to be removed because they are out of scope of the surveys. These adjustments are listed in Table 2.

First, we exclude 'other non-durable medical equipment' from the NHEA $(\$ 33,292$ million). This includes items such as non-prescription drugs, heating pads, bandages and other similar purchases about which the MEPS and MCBS do not collect information.

Second, we exclude expenditures on 'other health, residential and personal care expenditures' (\$77,597 million), which combines spending for health care in many different programs including school health, worksite health care, Medicaid home and community based waivers, some ambulance services, residential mental health and substance abuse facilities, and other types of health care provided in non-traditional settings. The largest public component is Medicaid spending and other personal services provided under home and community based waivers. Out of this $\$ 77,597$ million, $\$ 44,213$ million is paid by Medicaid and other state and federal programs. Following previous reconciliation work (Selden et.al (2001); Sing et al. (2006)), we exclude this entire category.

Third, we exclude graduate medical education and disproportionate share payment (\$17,000 million). Fourth, we exclude non-patient revenue $(\$ 54,599$ million) (i.e., revenue unrelated to the direct provision of medical services, received by health care providers) from each service category. Hospitals, for example, have non-patient revenue from gift shops and cafeterias, as well as from philanthropic donations. Such non-patient revenues are present in several service categories, including hospital, home health, nursing home, and physician and clinical care. Finally, we exclude services for foreign visitors in US (\$1,700 million).

Together, these exclusions reduce Personal Health Care services to $\$ 1,188$ billion compared to $\$ 1,372$ billion of unadjusted Personal Health Care. In total, we exclude about $\$ 184$ 
billion from the category of Personal Health Care as out-of-scope services expenditures. These exclusions are significantly smaller than those in Sing et.al (2006), where they removed about $\$ 377$ billion from Personal Health Care. The reason we remove $\$ 193$ billion less from the NHEA as compared to Sing et al. (2006) is that we complement MEPS with additional micro-surveys on the institutionalized population (MCBS, NNHS) and make additional adjustments (prison, military) to account for these expenditures.

\section{Alignment of Service Categories}

After we have made the out-of- scope exclusions from the NHEA, our goal is to match by service categories the total spending in the surveys to the adjusted total spending in the NHEA. Table 3 illustrates the mapping of service categories between the three sources. Owing to the tremendous detail available in the MEPS and MCBS, service categories can be constructed fairly consistently across the three sources. The few remaining differences in the categorization of expenditures are due to the differences in how each source assigns expenditure. For example, hospitals provide many services other than direct inpatient services. Expenditures classified as Hospital Care in the NHEA include revenue for room and board, ancillary services, physician services (which are not billed separately), inpatient pharmacy, hospital-based nursing home and hospital-based nursing home care (CMS, 2008(a)). The MEPS and MCBS, on the other hand, assign expenditure for these services to the prescription drug, nursing home and home health care categories, respectively. Selden et al. (2001) and Sing et al. (2006) make several other transfers and substitutions between service categories that are based on both published and unpublished data. 
For the most part, these transfers do not affect total NHEA expenditure but do cause differences in service-specific total expenditures between the studies. Also, different from our methods, Selden et al. (2001) and Sing et al. (2006) each separately reconcile Dental, Other Providers' and Other Medical Equipment between the MEPS and the NHEA, whereas we combine Other Providers with Physician and Clinical Services, and combine Dental and other Medical Equipment into the 'Other' category. These differences in methods do not cause differences in the overall adjustment rate but do contribute to discrepancies in service-specific expenditures between the MEPS micro survey and the NHEA totals. Following a previous reconciliation, we make several transfers between the NHEA defined service categories to other categories. Following previous work, we make two adjustments in the NHEA to reassign expenditure to be consistent with the MEPS and MCBS service categories. We use unpublished data provided to Meara, White and Cutler (2004) by the CMS Office of the Actuary on the proportion of public spending for home health and nursing home care (separately) used to purchase hospital-based care. These data cover 1990 to 2000, and we linearly extrapolate to 2002. Following Meara, White and Cutler (2004), we use these proportions to impute total spending on hospital-based home health and nursing care in 2002 ( $\$ 16$ billion and $\$ 13$ billion, respectively reported in Table 4). The imputed hospital-based values of Home Health and Nursing Home Care are calculated as follows: where $\mathrm{HBHH}_{\mathrm{IMP}}=[\mathrm{a} /(1-\mathrm{a})] * \mathrm{HH}_{\mathrm{NHEA}}$ and $\mathrm{HBNC}_{\mathrm{IMP}}=[\mathrm{b} /(1-\mathrm{b})]^{*} \mathrm{NC}_{\text {NHEA }} \mathrm{HH}_{\mathrm{NHEA}}$ and $\mathrm{NC}_{\text {NHEA }}$ are the NHEA Home Health and Nursing Care totals, $a$ and $b$ are the proportions of public spending on Home Health and Nursing Care used to purchase hospital-based services, and $\mathrm{HBHH}_{\mathrm{IMP}}$ and $\mathrm{HBNC}_{\mathrm{IMP}}$ are our imputed estimates. We implicitly assume that the same proportion of private expenditures purchase hospital-based services. Table 4 shows detailed transfers, which follows the work of Sing et al. 
(2006) unless otherwise noted. For example, we move $\$ 1,600$ million from Hospital to Other Personal Health Care and \$15,985 million from Hospital to Home Health. In total, we transfer 75,174 million (a little less than 7 percent of total adjusted NHEA) across service categories.

\section{Survey data adjustments}

In this section, we explain how we combine different surveys to have a nationally representative sample on population and spending. We use MEPS as the baseline survey, and add other surveys/data to account for missing population and spending in MEPS.

To better understand the health care expenditures made by the Medicare community population, we create a micro data file combining the MEPS and the MCBS data. To account for some missing independent variables (demographic) in the survey data, we use standard withinimputation methods (Rubin, 1987; Schenker and Raghunathan, 2007). This imputation helps us to use all available survey data without dropping any observations.

For Medicare-covered community residents, we adjust the sample weights to make sure that the combined surveys match national population totals. However, the MCBS and MEPS add to different population totals. In 2002, the Medicare-enrolled community-dwelling population is estimated at 37.6 million by MCBS (based on Medicare enrollment file) and 39.2 million by MEPS (Table 5). For this study, we presume the MCBS number is the most accurate (CMS data) and calibrate weighted totals in the MEPS to the match MCBS totals.

First, we calibrate the distribution of MEPS sample weights among that survey's respondents to the distribution found in the MCBS by medical expenditure, demographic, health status, and socioeconomic characteristics. To carry this out, we estimate a logistic regression predicting the propensity to be in the MEPS. We then use the propensity scores to create deciles of respondents with similar characteristics in both surveys. Within each decile, we inflate or 
deflate the MEPS weights to the MCBS weights. With these adjusted sample weights, MEPS and MCBS respondents with similar characteristics now have similar sample weights.

Our second set of adjustments corrects for double representation of the communitydwelling Medicare beneficiaries in the linked MEPS-MCBS data. For this group, we adjust individual sample weights in both surveys so that the sum of the combined data is equal to the sum of weights found in the MCBS. This adjustment reduces by one-half the individual weights in the MCBS and the calibrated weights in the MEPS.



In the MEPS-MCBS concatenated dataset, we have two sets of survey design parameters, with each survey using different sets of geographic areas to represent the nation. While there is potential for the sampled areas of one survey to overlap with the sampled areas of the other, MCBS and MEPS draw their samples in different ways; MCBS is an individual level survey with its own sampling frame, and MEPS is a household survey which uses the sampling frame from the prior year's National Health Interview Survey. Hence, we treat each survey's sampling strata and cluster pairs as statistically independent of each other.

Next, we account for the institutionalized population not covered by Medicare. Of the nearly 1.5 million people in nursing homes on a typical day in 2004, about 170,000 (or 12 percent) did not have Medicare coverage (National Center for Health Statistics, 2008). To account for this population, we increase the sample weights in the MCBS so that the sum of the weights among non-elderly institutionalized respondents reflects this additional population. We first sample records in the NNHS for people who are under age 65, and for whom nursing home 
services are not paid by Medicare. These records reflect a typical daily census, but this work requires having an annual total of people in an institution. We estimate this with two adjustments. The first is to adjust the weights so that the 2004 NNHS represents the estimated 2002 population. This adjustment factor is about 0.98 . The second is to adjust the weights to make the NNHS represent the yearly population in institutions rather than a count of people at one point in the year. This is calculated by comparing the MCBS and NNHS elderly populations. The adjustment factor for this rotational adjustment is approximately 2.89 .

We concatenate the adjusted NNHS data with records from the MCBS of non-elderly, Medicare-covered individuals who have institutional spending. To form demographically similar groups, we estimate a logistic model for being in the MCBS, using the demographic variables common to the two surveys as the independent variables. We assign respondents to propensity score quintiles based on having a similar likelihood of being in the MCBS. For each propensity score quintile, we increase sample weights among the MCBS respondents such that the sum of the new MCBS weights reflects the number of non-elderly institutionalized persons with nursing home stays throughout the year from the original MCBS and the NNHS matched data updated to the annual estimate. This adjustment assumes that the non-Medicare institutionalized are similar to the Medicare institutionalized, adjusted for age and other demographics.

To account for the prison population and those on active duty military within the United States, we adjust the sample weights among MEPS respondents without Medicare coverage. We start with state and federal prisoners. Data from the 2004 Survey of Inmates in State and Federal Correctional Facilities give a breakdown of prisoners by sex, age, race, and education. We use an adjustment factor of 1.005 to estimate 2002 numbers (Bureau of Justice Statistics). For each cell, we adjust upward the sample weights in the MEPS such that the adjusted population size for 
each group is equal to the size of the original MEPS population as well as the inmate population. In making this adjustment, we assume that prisoners with a particular age-sex-race-education profile have health expenses similar to those of community residents with the same profile.

Next, we use a similar method for active duty military. We use demographic tables on the five branches of the military for fiscal year 2003 as estimates of age-sex-race group sizes (Office of Army Demographics, 2003). We use an adjustment factor of 0.59 to account for active duty military within US.

Previous studies have shown that individuals with high health care expenditures are under-represented in the MEPS. Comparing the MEPS to Medicare claims data, Zuvekas et al. (2009) found a relative absence of high-spenders (expenditures $\$ 25,000$ and above) in the MEPS. Comparing the MCBS and the MEPS Medicare community sample, we estimate the percentage of high-spenders that are missing in the MEPS and adjust the MEPS weights to account for them. In the MEPS Medicare community sample, we increase the weights for highspenders by 1.14 . We also decrease the weights for low-spenders by 0.99 in order to keep the sample size intact. In total, we add about $\$ 8$ billion for missing high-spenders in the MEPS Medicare Community population.

We also adjust the MEPS weights to account for missing high-spenders in the nonMedicare population. We first estimate that there are about 2 million high-spenders in this population. Previously, from the concatenated MCBS-MEPS Medicare community data, we estimated the percentage of high-spenders that are missing in the MEPS. We assume the same number of missing in the non-Medicare population, and adjust the weights to account for them. We inflate the weights for high-spenders in the MEPS Medicare community sample by 1.14 and deflate the weights for low- spenders by 0.99 , keeping the non-Medicare community population 
intact. In total, we add about $\$ 15$ billion for the missing high-spenders in the MEPS nonMedicare community population.

\section{Results and Discussion}

Table 5 reports the sample sizes in the different surveys, weighted to reflect the 2002 population. The MEPS represents 285 million people, including 39 million Medicare enrolled elderly people living in communities. The MCBS represents 41 million beneficiaries covered by Medicare. Based on information from NNHS, the non-Medicare institutionalized population is estimated to be about 0.47 million. Prison inmates are estimated to be about 1.4 million, and active duty military within U.S. about 0.9 million.

Table 6 show the healthcare spending by service type (hospital care, physician and clinical services, prescription drugs, etc.), and what portion is funded by Medicare and what portion is non-Medicare funded. Out of a total of $\$ 1,187,763$ million in personal healthcare spending, Medicare paid $\$ 251,714$ million and the rest $\$ 936,049$ million is non-Medicare spending. Approximately, $21 \%$ was paid by Medicare.

Table 7 compares total annual medical expenditure from the adjusted MEPS and MCBS to total adjusted NHEA spending, by payer and service category. Overall, the survey spending underestimates national spending by $12.7 \%$. Our estimates using the adjusted micro surveys are closest to the adjusted NHEA estimates for prescribed medicines, nursing home care, and other services (including dental care and durable medical equipment (DME)). In addition, our estimates for expenditures made under the Medicare program are much closer to the NHEA than for non-Medicare payers. The last column in Table 7 reports how much survey-reported spending would have to be adjusted in order to equal adjusted NHEA spending. 
Figure 1 gives a comprehensive account of this reconciliation study. The NHEA estimated Personal Health Care expenditures in 2002 are about $\$ 1,372$ billion, and the national micro-surveys accounted for $\$ 1,036$ billion. Of the $\$ 336$ billion in expenditures that is unaccounted for, we know that $\$ 184$ billion is out of scope (See Table 2 for details) of the micro-surveys. The remaining $\$ 152$ billion is an undercount of spending in the micro-surveys and we make adjustment to spending by service category to match the national totals (Table 7).

This may be mostly due to under-reporting of medical expenditures for the non-Medicare community population in MEPS. Under-reporting was found to be the most common problem in a review of 42 studies evaluating the accuracy of self-reported health care utilization data (Bhandari and Wagner, 2006). Households report their own out-of-pocket payments fairly well (Machlin et al., 1999), but may not know third party payments at all or report them inaccurately because of confusion about discounts and contractual arrangements between provider and third party payers. (Zuvekas et al., 2009).

Our adjusted NHEA for 2002 is $\$ 1,036$ billion as compared to $\$ 964$ billion in Sing et al. (2006). Thus, our reconciliation removes approximately $\$ 184$ billion from the NHEA as compared to $\$ 408$ billion in Sing et al. (2006). Our total expenditure estimates from MEPS and additional surveys micro-surveys is \$1,036 billion. In Sing et al. (2006) the total adjusted MEPS expenditure was $\$ 831$ billion (pooled sample of 2002 and 2003). We reconcile an additional \$205 billion as compared to Sing et al. (2006). This is possible because we have included the institutionalized population not covered by MEPS.

Out of $\$ 1,036$ billion reconciled by different surveys: non-Medicare community population spending was $\$ 498$ billion, Medicare community spending was $\$ 307$ billion, and 
spending on the institutionalized population, high-spenders and those in prison $\&$ the military was $\$ 205, \$ 23$ and $\$ 3$ billion dollar respectively.

\section{Limitations}

It is important to keep in mind that this reconciliation requires several assumptions. Differences between our estimates and the adjusted NHEA for specific service categories may be caused by remaining differences in how services are defined in the surveys versus the NHEA. Thus, the aggregate totals may be more important than the sub-categories. Further, in adjusting the sample weights to account for sub-populations not covered in the MEPS and MCBS (nonelderly institutionalized, prison inmates, and active duty military personnel), we implicitly assume that their health expenditures (adjusted for demographics) are the same as in the population we can observe. This assumption may not always be accurate.

\section{Conclusions}

The major comparison for our work is the work of Sing et al. (2006). We follow many of their adjustments to the NHEA, but direct comparison of the estimates is difficult. We remove less spending from the NHEA, and use the concatenated Medicare community MEPS-MCBS, MCBS institutionalized data, and MEPS non-Medicare data with adjustments for excluded populations.

We construct a more comprehensive dataset of medical spending by American citizens than has been done in the past, using both the MCBS and MEPS, and accounting for the institutionalized population, prison inmates, active duty military personnel, and high-spenders. We reconcile this linked and enhanced MEPS-MCBS dataset to the NHEA, building upon a rich 
body of prior work by AHRQ and CMS. In total, we remove only 13.4 percent from personal health care in the NHEA as out-of-scope, and reconcile to remaining comparable spending from the micro expenditure surveys. This enhanced MEPS-MCBS dataset matched to the NHEA can be used for more detailed policy evaluations that more closely reflect true national personal health expenditure at the individual level. 


\section{References}

[1] Adler, G.S. (1994). A Profile of the Medicare Current Beneficiary Survey. Health Care Financing Review, 15(4), 153-163.

[2] Agency for Healthcare Research and Quality (AHRQ). (2016). Medical Expenditure Panel Survey, http://www.meps.ahrq.gov/mepsweb/data_stats/data_overview.jsp

[3] Aizcorbe A., Retus B., Smith S. (2008). Toward a Health Care Satellite Account. Survey of Current Business, 88(5), 24-30.

[4] Arnett, R.H., Blank, L.A., Brown, A.P. et al. (1990a): National Health Expenditures, 1988. Health Care Financing Review, 11(4), 1-41.

[5] Arnett, R.H., Blank L.A., Brown A.P. et al. (1990b). Revisions to the National Health Accounts and Methodology. Health Care Financing Review, 11(4), $42-54$.

[6] Bernard, D., Cowan, C., Selden, T., Cai, L., Catlin, A., \& Heffler, S. (2012). Reconciling Medical Expenditure Estimates from the MEPS and NHEA, 2007. Medicare \& Medicaid Research Review, 2(4), E1-E19.

[7] Bhandari, A., Wagner T. (2006). Self-Reported Utilization of Health Care Services:

Improving Measurement and Accuracy. Medical Care Research and Review, 63(2), 217-235.

[8] Centers for Medicare \& Medicaid Services. National Health Expenditure Accounts:

Definitions, Sources and Methods Used in the NHEA, 2011.

Available at: http://www.cms.gov/Research-Statistics-Data-and-Systems/Statistics-Trends-and-

Reports/NationalHealthExpendData/NationalHealthAccountsHistorical.html

[9] Centers for Medicare \& Medicaid Services: Medicare Current Beneficiary Survey. Internet address: https://www.cms.gov/Research-Statistics-Data-and-Systems/Files-for-

Order/LimitedDataSets/MCBS.html

[10] Cohen, J.W., Monheit, A.C, Beauregard, K.M et al. (1996). The Medical Expenditure Panel Survey: A National Heath Information Resource. Inquiry, 33(4), 373-389.

[11] Cohen, J.W. (1997). Design and Methods of the Medical Expenditure Panel Survey Household Component. MEPS Methodology Report no. 1, AHCPR Pub. No. 97-0026. Rockville, Md.: Agency for Health Care Policy and Research (AHCPR).

[12] Cohen, J.W., et al. (2009) . A National Information Resource to Support Health Care Research and Inform Policy and Practice. Medical Care, Vol 47, November 7, Supplement 1.

[13] Finkelstein, E.A., Trogdon, J.G., Cohen, J.W., \& Dietz, W. (2009). Annual Medical Spending Attributable To Obesity: Payer-And Service-Specific Estimates. Health Affairs, 28(5), w822-w831. 
[14] Fisher C.R. (1980). Differences by Age Groups in Health Care Spending. Health Care Financing Review, 1(3), 65-90.

[15] Machlin, S.R., Cohen J.W., Zuvekas S.H. and Thorpe J.M. (1999). Accuracy of Household Reported Payments for Physician Visits in 1996 Medical Expenditure Panel Survey. Proceedings of the American Statistical Association of the Section on Survey Research Methods.

[16] Meara, E., White, C., \& Cutler, D. M. (2004). Trends in Medical Spending By Age, 19632000. Health Affairs, 23(4), 176-183.

[17] National Center for Health Statistics: National Nursing Home Survey. Internet address: http://www.cdc.gov/nchs/nnhs.htm

[18] National Center for Health Statistics: Health, United States, 2006. With Chartbook on Trends in the Health of Americans. Hyattsville, MD: 2006.

[19] National Center for Health Statistics: Variance estimation and other analytic issues in the 1997-2005 NHIS. Internet address: http://www.cdc.gov/nchs/data/nhis/9705var.pdf

[20] Office of Army Demographics: Fiscal Year 03 Profile of Army, Fiscal Year 03 Profile of Navy, Fiscal Year 03 Profile of Marine Corps, Fiscal Year 03 Profile of Air Force, Fiscal Year 03 Profile of Coast Guard.

[21] Ormond, B. A., Spillman, B. C., Waidmann, T. A., Caswell, K. J., \& Tereshchenko, B. (2011). Potential National and State Medical Care Savings from Primary Disease Prevention. Am J Public Health American Journal of Public Health, 101(1), 157-164.

[22] Roehrig, C., Miller, G., Lake, C., \& Bryant, J. (2009). National Health Spending By Medical Condition, 1996-2005. Health Affairs, 28(2), w358-w367.

[23] Rosen A, Cutler D. (2007). Measuring Medical Care Productivity. A Proposal for U.S. National Health Accounts. Survey of Current Business, 87(6): 54-58.

[24] Rosen A, Cutler D. (2009) Challenges in Building Disease-Based National Health Accounts. Medical Care, 47(7), S7-S13.

[25] Rubin, D.B. (1987). Multiple Imputation for Nonresponse in Surveys. Wiley Series in Probability and Statistics.

[26] Schenker, N., \& Raghunathan, T. E. (2007). Combining information from multiple surveys to enhance estimation of measures of health. Statistics in Medicine, 26(8), 1802-1811.

[27] Sabol J.W, Mintin T.D., Harrison M.P. (2008). Prison and Jail Inmates at Midyear 2006. June 28, 2007, NCJ 217675 
[28] Selden T., Levit K., Cohen J., et al. (2001). Reconciling Medical Expenditure Estimates from the MEPS and the NHA, 1996. Health Care Financing Review, 23, 161-178.

[29] Sing M., Banthin J.S., Selden T.M., et al. (2006). Reconciling Medical Expenditure Estimates from the MEPS and the NHEA, 2002. Health Care Financing Review, 28, 25-40.

[30] U.S. Department of Justice, Bureau of Justice Statistics.: Survey of Inmates in State and Federal Correctional Facilities, 2004 Bibliographic Citation: [Computer file]. ICPSR04572-v1. Ann Arbor, MI: Inter-university Consortium for Political and Social Research, 2007-02-28.

[31] Waldo, D.R, Sonnerfeld, S.T, Mckusick D.R., et al. (1989) Health Expenditures by Age Group, 1977 and 1987. Health Care Financing Review, 10(4), 111-120.

[32] Zuvekas, S. H., \& Olin, G. L. (2009). Accuracy of Medicare Expenditures in the Medical Expenditure Panel Survey. Inquiry, 46(1), 92-108. 
Table 1 : National Health Expenditures, by Source of Funds and Type of Expenditure (in millions) : 2002

\begin{tabular}{|c|c|c|c|c|c|c|c|c|c|c|}
\hline & Total & $\begin{array}{l}\begin{array}{l}\text { Out of } \\
\text { Pocket }\end{array} \\
\end{array}$ & $\begin{array}{l}\text { Health } \\
\text { Insurance }\end{array}$ & $\begin{array}{l}\text { Private } \\
\text { Health } \\
\text { Insurance }\end{array}$ & Medicare & Medicaid & $\begin{array}{l}\text { Other } \\
\text { Health } \\
\text { Insurance } \\
\text { Programs }{ }^{1} \\
\end{array}$ & $\begin{array}{l}\text { Other } \\
\text { Third } \\
\text { Party } \\
\text { Payers }\end{array}$ & $\begin{array}{l}\text { Public } \\
\text { Health } \\
\text { Activity }\end{array}$ & Investment \\
\hline National Health Expenditures & $1,636,416$ & 222,194 & $1,120,549$ & 560,460 & 264,587 & 248,218 & 47,284 & 139,759 & 51,870 & 102,044 \\
\hline Health Consumption Expenditures & $1,534,372$ & 222,194 & $1,120,549$ & 560,460 & 264,587 & 248,218 & 47,284 & 139,759 & 51,870 & $\mathrm{x}$ \\
\hline Personal Health Care & $1,371,951$ & 222,194 & $1,019,750$ & 488,499 & 255,757 & 230,096 & 45,399 & 130,007 & $\mathrm{x}$ & $\mathrm{x}$ \\
\hline Hospital Care & 486,477 & 15,274 & 424,235 & 170,622 & 142,737 & 84,852 & 26,024 & 46,969 & $\mathrm{x}$ & $\mathrm{x}$ \\
\hline Professional Services & 458,207 & 80,255 & 332,782 & 217,289 & 74,863 & 29,834 & 10,796 & 45,171 & $\mathrm{x}$ & \\
\hline Physician and Clinical Expenditures & 340,852 & 35,398 & 265,416 & 163,722 & 68,041 & 23,916 & 9,738 & 40,038 & $\mathrm{x}$ & $\mathrm{x}$ \\
\hline Dental Services & 73,684 & 32,315 & 41,052 & 36,563 & 79 & 3,472 & 939 & 317 & $\mathrm{x}$ & $\mathrm{x}$ \\
\hline Other Professional Services & 43,671 & 12,542 & 26,314 & 17,005 & 6,744 & 2,446 & 119 & 4,815 & $\mathrm{x}$ & $\mathrm{x}$ \\
\hline Other Health, Residential, and Personal Care Expenditures & 77,597 & 4,488 & 47,235 & 3,022 & 2,368 & 39,998 & 1,847 & 25,874 & $\mathrm{x}$ & $\mathrm{x}$ \\
\hline Home Health Care & 36,628 & 6,135 & 27,737 & 6,476 & 11,338 & 9,791 & 133 & 2,756 & $\mathrm{x}$ & $\mathrm{x}$ \\
\hline Nursing Care Facilities \& Cont. Care Retirement Communities & 94,480 & 27,941 & 60,881 & 8,180 & 15,026 & 35,482 & 2,194 & 5,657 & $\mathrm{x}$ & $\mathrm{x}$ \\
\hline Retail Outlet Sales of Medical Products & 218,562 & 88,101 & 126,881 & 82,909 & 9,425 & 30,140 & 4,407 & 3,580 & $\mathrm{x}$ & $\mathrm{x}$ \\
\hline Prescription Drugs & 158,174 & 41,196 & 113,900 & 79,649 & 2,472 & 27,443 & 4,336 & 3,079 & $\mathrm{x}$ & $\mathrm{x}$ \\
\hline Durable Medical Equipment & 27,095 & 15,289 & 11,305 & 3,260 & 5,277 & 2,697 & 71 & 501 & $\mathrm{x}$ & $\mathrm{x}$ \\
\hline Other Non-Durable Medical Products & 33,292 & 31,616 & 1,676 & $\mathrm{x}$ & 1,676 & $\mathrm{x}$ & $\mathrm{x}$ & 0 & $\mathrm{x}$ & $\mathrm{x}$ \\
\hline Net Cost of Health Insurance & 88,927 & $\mathrm{x}$ & 81,369 & 71,962 & 3,731 & 5,222 & 454 & 7,559 & $\mathrm{x}$ & $\mathrm{x}$ \\
\hline Government Administration & 21,624 & $\mathrm{x}$ & 19,430 & $\mathrm{x}$ & 5,099 & 12,900 & 1,432 & 2,194 & $\mathrm{x}$ & $\mathrm{x}$ \\
\hline Government Public Health Activities & 51,870 & $\mathrm{x}$ & $\mathrm{x}$ & $\mathrm{x}$ & $\mathrm{x}$ & $\mathrm{x}$ & $\mathrm{x}$ & $\mathrm{x}$ & 51,870 & $\mathrm{x}$ \\
\hline Investment & 102,044 & $\mathrm{x}$ & $\mathrm{x}$ & $\mathrm{x}$ & $\mathrm{x}$ & $\mathrm{x}$ & $\mathrm{x}$ & $\mathrm{x}$ & $\mathrm{x}$ & 102,044 \\
\hline Research & 32,016 & $\mathrm{x}$ & $\mathrm{x}$ & $\mathrm{x}$ & $\mathrm{x}$ & $\mathrm{x}$ & $\mathrm{x}$ & $\mathrm{x}$ & $\mathrm{x}$ & 32,016 \\
\hline Structure and Equipment & 70,028 & $\mathrm{x}$ & $\mathrm{x}$ & $\mathrm{x}$ & $\mathrm{x}$ & $\mathrm{x}$ & $\mathrm{x}$ & $\mathrm{x}$ & $\mathrm{x}$ & 70,028 \\
\hline
\end{tabular}

1. Includes Children's Health Insurance Program (Titles XIX and XXI), Department of Defense, and Department of Veterans' Affairs.

2. Source: 2010 Edition of the 2002 NHEA 
Table 2. Adjustments to the 2002 National Health Expenditure Accounts: Exclusions

\begin{tabular}{|c|c|c|c|}
\hline $\begin{array}{l}\text { Health Care Service or Type of } \\
\text { Expenditure }\end{array}$ & $\begin{array}{l}\text { Amount, in } \\
\text { Millions }\end{array}$ & Category of Service & Payers \\
\hline \multicolumn{4}{|c|}{ I. Exclusions for Out-of-Scope Services or Expenditure } \\
\hline Other Non-Durable Medical Equipment ${ }^{\mathrm{a}, \mathrm{b}}$ & $\$ 33,292$ & Other Non-DME & All, Medicare, Non-Medicare \\
\hline $\begin{array}{l}\text { Other Health, Residential and Personal } \\
\text { Health Care }{ }^{b}\end{array}$ & $\$ 77,597$ & Other PHC & All, Medicare, Non-Medicare \\
\hline $\begin{array}{l}\text { Graduate Medical Education and Disprop. } \\
\text { Share Payments }{ }^{b}\end{array}$ & $\$ 17,000$ & Hospital Care & All, Medicare \\
\hline Non-Patient Revenue ${ }^{a}$ & $\$ 54,599$ & Multiple & All, Non-Medicare \\
\hline \multicolumn{4}{|l|}{ II. Exclusions for Out-of-Scope Populations } \\
\hline Foreign Visitors $^{\mathrm{b}}$ & $\$ 1,700$ & Multiple & All, Non-Medicare \\
\hline Total Exclusions & $\$ 184,188$ & & \\
\hline
\end{tabular}


Table 3: Mapping Between NHEA, MEPS, and MCBS Service Categories

\begin{tabular}{|c|c|c|c|}
\hline New Category & NHEA Categories & MEPS Categories & MCBS Categories \\
\hline $\begin{array}{l}\text { Physician \& } \\
\text { Clinical Services }\end{array}$ & $\begin{array}{l}\text { - Physician and Clinical } \\
\text { Services } \\
\text { - Other Professional } \\
\text { Services }\end{array}$ & $\begin{array}{l}\text { - Office-based care } \\
\text { - Outpatient provider } \\
\text { - Emergency room MD } \\
\text { - Hospital stays MD }\end{array}$ & - Medical providers \\
\hline Hospital Care & Hospital & $\begin{array}{l}\text { - ER facility } \\
\text { - Hospital Inpatient facility } \\
\text { - Outpatient facility }\end{array}$ & $\begin{array}{l}\text { - All inpatient sources, } \\
\text { including ER visits } \\
\text { - Outpatient services }\end{array}$ \\
\hline $\begin{array}{l}\text { Home Health } \\
\text { Care }\end{array}$ & Home Health & $\begin{array}{l}\text { - Home health agency } \\
\text { - Home health non-agency }\end{array}$ & - All home health sources \\
\hline $\begin{array}{l}\text { Prescription } \\
\text { Drugs }\end{array}$ & Prescription Drugs & - Prescription medications & $\begin{array}{l}\text { - All prescription medical } \\
\text { sources }\end{array}$ \\
\hline $\begin{array}{l}\text { Nursing Home } \\
\text { Care }\end{array}$ & Nursing Home & Not measured & $\begin{array}{l}\text { - Nursing home care } \\
\text { - Hospice care } \\
\text { - Short-term facility } \\
\text { (usually SNF) }\end{array}$ \\
\hline Other & $\begin{array}{l}\text { - Dental Services } \\
\text { - Non-Durable Medical } \\
\text { Equipment }\end{array}$ & $\begin{array}{l}\text { - Dental care } \\
\text { - Glasses/contact lenses } \\
\text { - Other equipment and } \\
\text { supplies (except diabetes) }\end{array}$ & $\begin{array}{l}\text { - All dental sources } \\
\text { - Vision medical items } \\
\text { - Durable medical } \\
\text { equipment }\end{array}$ \\
\hline
\end{tabular}


Table 4. Adjustments to the 2002 National Health Expenditure Accounts: Transfers

\begin{tabular}{|c|c|c|c|}
\hline $\begin{array}{l}\text { Health Care Service or Type of } \\
\text { Expenditure }\end{array}$ & $\begin{array}{c}\text { Amount, in } \\
\text { Millions }\end{array}$ & Category of Service & Payers \\
\hline \multicolumn{4}{|l|}{ Transfers between Service Categories } \\
\hline Hospital-Based Personal Health Care ${ }^{a}$ & $\$ 1,600$ & Hospital to Other PHC & All, Non-Medicare \\
\hline Hospital-Based Home Health Care ${ }^{b}$ & $\$ 15,985$ & Hospital to Home Health & All, Medicare, Non-Medicare \\
\hline Hospital-Based Nursing Home Care ${ }^{b}$ & $\$ 13,089$ & Hospital to Nursing Home Care & All, Medicare, Non-Medicare \\
\hline DME provided by Physicians ${ }^{\text {a }}$ & $\$ 2,200$ & Physician to Other & All, Medicare, Non-Medicare \\
\hline Rx supplied in Hospitals ${ }^{\text {a }}$ & $\$ 3,400$ & Hospital to $\mathrm{Rx}$ & All, Medicare, Non-Medicare \\
\hline Rx supplied by Physicians ${ }^{a}$ & $\$ 5,200$ & Physician to $\mathrm{Rx}$ & All, Medicare, Non-Medicare \\
\hline $\begin{array}{l}\text { Other Professional Services provided in } \\
\text { Physician Offices }{ }^{\text {a }}\end{array}$ & $\$ 33,700$ & Physician to Other Professional & All, Medicare, Non-Medicare \\
\hline Total Transfers & $\$ 75,174$ & & \\
\hline
\end{tabular}


Table 5. Data Sources and Population: 2002

\begin{tabular}{llcc}
\hline Population Group & Description & Source & $\begin{array}{c}\text { Estimated } \\
\text { Population } \\
\text { Size }\end{array}$ \\
\hline Non-Institutionalized & Adult and children residing in the community & MEPS & $246,123,026$ \\
\hline Non-Medicare & Elderly and disabled residing in the community & MEPS & $39,219,603$ \\
Medicare enrolled & Elderly and disabled residing in the community & MCBS & $37,659,510$ \\
Institutionalized & & NNHS,MCBS & 467,430 \\
\hline Non-Medicare & & Adults and children with institutional stays & MCBS \\
Medicare enrolled & Elderly and disables with institutional stays & $4,148,881$ \\
Other Groups & & Inmates of state and federal prisons & \\
\hline Prison inmates & & Active members of the five military branches within US & DMRC \\
\hline Active Duty Military & & & 860,011
\end{tabular}

Sources: 2002 Medical Expenditure Panel Survey(MEPS), 2002 Medicare Current Beneficiary Survey(MCBS), 2004

National Nursing Home Survey (NNHS), data from the office of Army Demographics(fiscal year 2003), 2004 Survey of Inmates and Federal Correction Facilities

${ }^{1}$ Annualized estimate based on daily basis 
Table 6. 2002 Adjusted National Health Expenditures, in Millions

\begin{tabular}{lccc} 
& \multicolumn{3}{c}{ Payers } \\
\cline { 2 - 3 } Hospital Care & All Payers & Medicare & Non-Medicare \\
Home Health & $\$ 413,658$ & $\$ 134,466$ & $\$ 279,192$ \\
Nursing Home Care & $\$ 51,513$ & $\$ 16,439$ & $\$ 35,074$ \\
Physician and Clinical Services & $\$ 103,626$ & $\$ 17,198$ & $\$ 86,428$ \\
Other Professional Services & $\$ 275,095$ & $\$ 59,837$ & $\$ 215,258$ \\
Prescription Drugs & $\$ 74,421$ & $\$ 13,471$ & $\$ 60,950$ \\
Other (Vision, Dental \& Durable & $\$ 166,552$ & $\$ 4,508$ & $\$ 162,045$ \\
Medical Equipment) & & & \\
\hline & $\$ 102,898$ & $\$ 5,795$ & $\$ 97,103$ \\
\hline
\end{tabular}

Source: 2010 edition of the 2002 NHEA. 
Table 7. Comparison of 2002 MEPS-MCBS Annual Expenditures and 2002 Adjusted-NHEA Annual Expenditures

\begin{tabular}{|c|c|c|c|c|}
\hline Payer & Service & $\begin{array}{l}\text { Adjusted } \\
\text { Total Annual } \\
\text { Expenditure } \\
\text { (in millions) } \\
\end{array}$ & $\begin{array}{l}\text { Adjusted } \\
\text { NHEA } \\
\text { Expenditure } \\
\text { (in millions) } \\
\end{array}$ & $\begin{array}{l}\text { Adjustment } \\
\text { Factor }^{1}\end{array}$ \\
\hline \multirow[t]{8}{*}{ All Payers } & Total & $1,036,231$ & $1,187,763$ & 1.15 \\
\hline & Hospital Care & 373,443 & 413,658 & 1.11 \\
\hline & Physician and Clinical Services & 208,113 & 275,095 & 1.32 \\
\hline & Other Professional Services & 49,031 & 74,421 & 1.52 \\
\hline & Home Health & 34,790 & 51,513 & 1.48 \\
\hline & Prescribed Medicines & 156,883 & 166,552 & 1.06 \\
\hline & Nursing Home Care & 119,108 & 103,626 & 0.87 \\
\hline & Other(Dental, DME) & 94,863 & 102,898 & 1.08 \\
\hline \multirow[t]{8}{*}{ Medicare } & Total & 265,427 & 251,714 & 0.95 \\
\hline & Hospital Care & 154,155 & 134,466 & 0.87 \\
\hline & Physician and Clinical Services & 58,280 & 59,837 & 1.03 \\
\hline & Other Professional Services & 6,148 & 13,471 & 2.19 \\
\hline & Home Health & 16,203 & 16,439 & 1.01 \\
\hline & Prescribed Medicines & 6,493 & 4,508 & 0.69 \\
\hline & Nursing Home Care & 16,370 & 17,198 & 1.05 \\
\hline & Other(Dental, DME) & 7,778 & 5,795 & 0.75 \\
\hline \multirow[t]{8}{*}{ Non-Medicare } & Total & 770,804 & 936,049 & 1.21 \\
\hline & Hospital Care & 219,288 & 279,192 & 1.27 \\
\hline & Physician and Clinical Services & 149,833 & 215,258 & 1.44 \\
\hline & Other Professional Services & 42,883 & 60,950 & 1.42 \\
\hline & Home Health & 18,587 & 35,074 & 1.89 \\
\hline & Prescribed Medicines & 150,390 & 162,045 & 1.08 \\
\hline & Nursing Home Care & 102,738 & 86,428 & 0.84 \\
\hline & Other(Dental, DME) & 87,085 & 97,103 & 1.12 \\
\hline
\end{tabular}

Source: 2002 MEPS, 2002 MCBS, 2010 edition of 2002 NHEA.

${ }^{1}$ The ratio of annual expenditure totals in the adjusted NHEA relative to totals in the linked MEPS-MCBS data. 


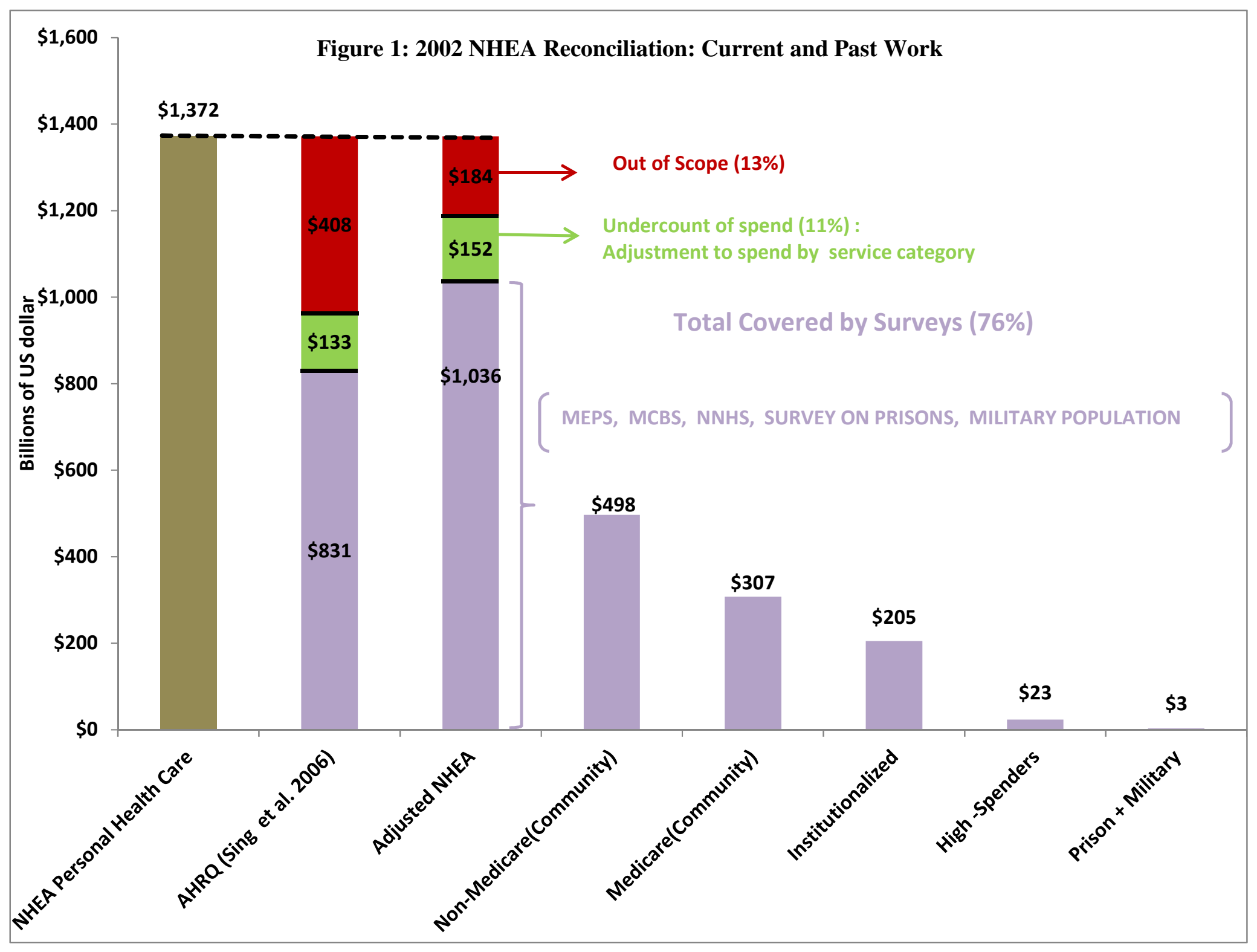

